\title{
A kinetic reaction model for biomass pyrolysis processes in Aspen Plus
}

Jens F. Peters ${ }^{1,2}$, Scott W. Banks ${ }^{3}$, Anthony V. Bridgwater ${ }^{3}$, Javier Dufour ${ }^{4,5}$

${ }^{1}$ Research Group Resources, Recycling, Environment \& Sustainability, Helmholtz-Institute Ulm (HIU). Karlsruhe (Germany)

${ }^{2}$ Karlsruhe Institute for Technology (KIT). Karlsruhe (Germany)

${ }^{3}$ EBRI European Bioenergy Research Institute, Aston University. Birmingham (UK).

${ }^{4}$ Department of Chemical and Energy Technology, Rey Juan Carlos University. Móstoles (Spain).

${ }^{5}$ Systems Analysis Unit, Instituto IMDEA Energía. Móstoles (Spain)*

\section{Abstract}

This paper presents a novel kinetic reaction model for biomass pyrolysis processes. The model is based on the three main building blocks of lignocellulosic biomass, cellulose, hemicellulose and lignin and can be readily implemented in Aspen Plus and easily adapted to other process simulation software packages. It uses a set of 149 individual reactions that represent the volatilization, decomposition and recomposition processes of biomass pyrolysis. A linear regression algorithm accounts for the secondary pyrolysis reactions, thus allowing the calculation of slow and intermediate pyrolysis reactions. The bio-oil is modelled with a high level of detail, using up to 33 model compounds, which allows for a comprehensive estimation of the properties of the bio-oil and the prediction of further upgrading reactions. After showing good agreement with existing literature data, our own pyrolysis experiments are reported for validating the reaction model. A beech wood feedstock is subjected to pyrolysis under welldefined conditions at different temperatures and the product yields and compositions are determined. Reproducing the experimental pyrolysis runs with the simulation model, a high coincidence is found for the obtained fraction yields (bio-oil, char and gas), for the water content and for the elemental composition of the pyrolysis products. The kinetic reaction model is found to be suited for predicting pyrolysis yields and product composition for any lignocellulosic biomass feedstock under typical pyrolysis conditions without the need for experimental data.

\section{Keywords:}

Aspen Plus, bio-oil, lignocellulosic biomass, process simulation, pyrolysis, reaction kinetics

* The development of the kinetic reaction model and its bibliographic validation was carried entirely out at IMDEA Energy Institute, while the experimental validation was done at EBRI. 
An efficient deployment of the existing bioenergy potential is vital for reaching the renewable energy targets set up by the European Union [1]. However, biomass is a decentrally available energy source of relatively low density. This increases expenses for handling and transport and thereby limits the potential for industrial applications. One possibility to overcome this problem is the use of fast pyrolysis for converting the biomass into bio-oil and / or char. Pyrolysis is the thermal decomposition under non-oxidative atmosphere and at moderate temperatures, normally around $500{ }^{\circ} \mathrm{C}$. With lignocellulosic biomass as feedstock, it yields gases, a carbonaceous residue (char) and a liquid fraction (bio-oil). The bio-oil has a similar heating value as the original biomass, but a higher density and, as a liquid, it is easier to handle [2]. By varying the reaction conditions, the yield of the fractions can be controlled: Fast pyrolysis maximizes the liquid yield at temperatures around $500{ }^{\circ} \mathrm{C}$ and very short residence times, while slow pyrolysis achieves high char yields at slightly lower temperatures around $450{ }^{\circ} \mathrm{C}$ and very long vapour residence times [3]. Biomass pyrolysis is mainly in the research stage and almost no commercial pyrolysis installations exist to-date [4,5]. Due to the lack of actual plant data, system analysis of pyrolysis processes is normally based on process simulation. Since bio-oil is a complex substance composed of hundreds of individual compounds $[3,6]$, its modelling in process simulations is a difficult task and requires major simplifications. Existing technical and environmental assessments use approximations applying few model compounds, significantly simplifying the bio-oil characteristics. Furthermore, they use to implement simple top-down approaches which adjust the pyrolysis products of the reactor to existing literature data for a specific feedstock [714]. This creates a dependency on experimental data and makes it difficult to simulate processes with feedstock for which no experimental data is available. To avoid this drawback, a flexible and predictive simulation capable of dealing with a wide range of different lignocellulosic feedstock is of considerable interest. Kinetic reaction models based on thermodynamic equilibrium calculations can provide this flexibility and have been developed for combustion or gasification reactions [15-17], but proven to be unsuitable for predicting pyrolysis reactions [18]. Current approaches for modelling pyrolysis processes focus strongly on computational fluid dynamic (CFD)[19-21] or single particle models [22,23], while others consider isolated biomass components (like e.g. lignin) [24] or determine only the lumped yields of the principal pyrolysis products (gas, char, oil) [25-30], while they do not model their detailed composition. Nevertheless, the latter is of high importance for system analysis, since emissions and other environmental impacts of the process are determined to a major share by the composition of the products i.e., their content of nitrogen, chlorine, sulphur etc. Knowing the detailed composition of the bio-oil is also relevant for modelling downstream processes like the refining / upgrading of the bio-oil to transportation fuel. Still, no work has yet been published that allows a predictive calculation of the composition of pyrolysis products for varying feedstocks [31]. This paper presents a kinetic reaction model able to calculate yields and composition of the pyrolysis products of unknown lignocellulosic feedstock based on its biochemical composition and with a minimum of input. The model can be readily implemented in Aspen Plus. In this way, independency from experimental data is achieved and a valuable tool for system analysis of pyrolysis processes for lignocellulosic biomass is provided. It can be used for assessing fast and slow pyrolysis processes on plant and component level, and permits predicting also the influence of different reactor conditions on the pyrolysis product properties [32-35]. Cross-checking the 
results obtained from the reaction model with data obtained from specific pyrolysis experiment further allows for its validation.

\section{Reaction model}

The kinetic reaction scheme presented in this work follows the model approach of DiBlasi et al. [36], assuming an interlinked linear reaction process for the three basic biomass building blocks (cellulose, hemicellulose and lignin) [37,31]. It takes into account the primary pyrolysis reactions as well as the secondary cracking reactions. For this purpose, the pyrolysis mechanism is divided in three phases, one decomposition phase and two pyrolysis phases. Figure 1 schematically depicts the reaction mechanism implemented.

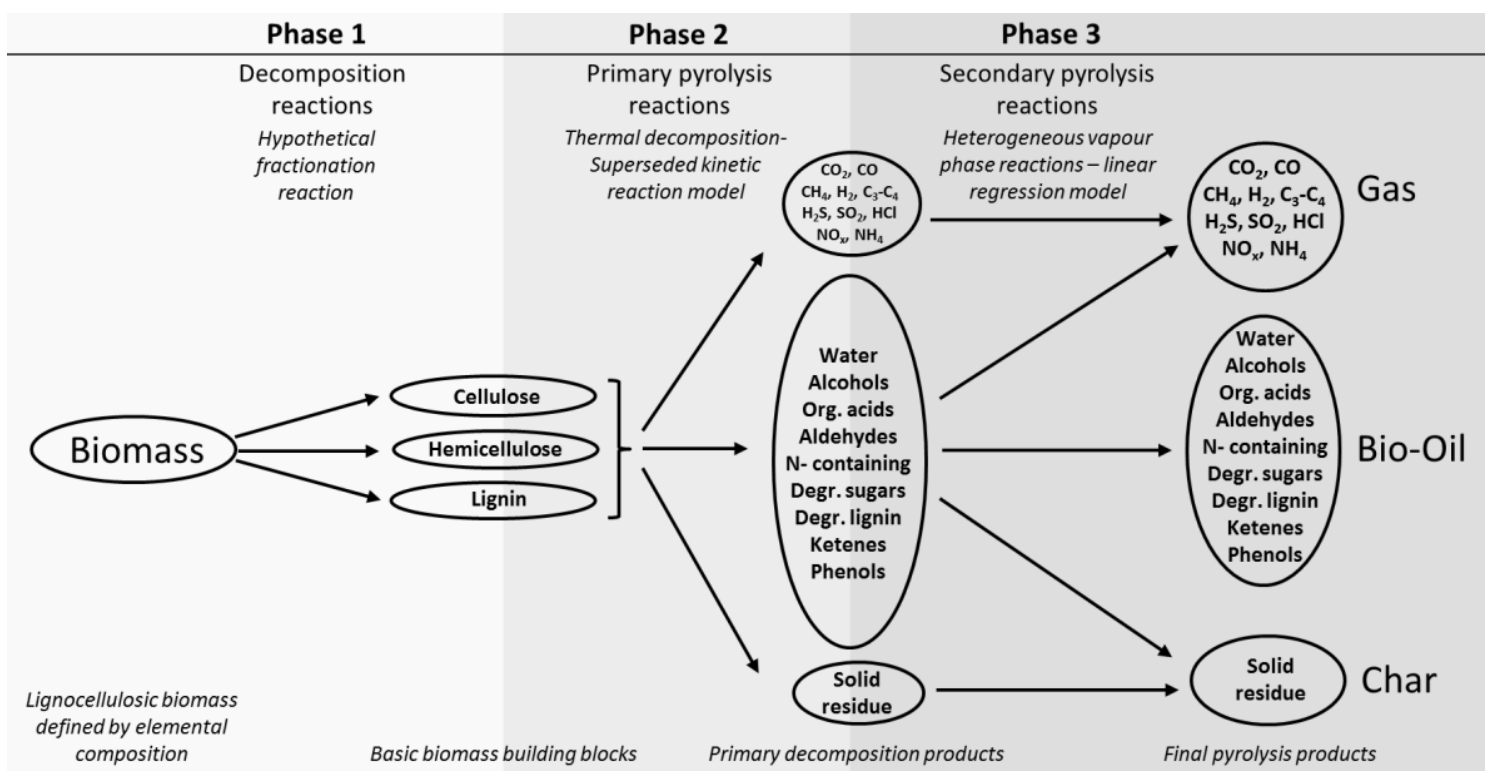

Figure 1. Three stage reaction scheme for pyrolysis reactions as implemented in the simulation

The first phase is a virtual reaction step that decomposes the biomass into its three principal biochemical building blocks, cellulose, hemicellulose and lignin. The second phase represents the decomposition and volatilization of the biomass fragments, giving a high liquid yield. This is the dominating reaction mechanism for fast pyrolysis processes with short vapour residence times. The third phase contains the secondary cracking and charring reactions which increase gas and char yields at the expense of liquid yield, due to secondary (catalytic) cracking reactions. These gain importance with increasing residence times and are therefore especially relevant for slow and intermediate pyrolysis reactions.

From the kinetic reaction modelling, the model is able to calculate the yields of key pyrolysis products for a temperature range between 420 to $650{ }^{\circ} \mathrm{C}$ and for hot vapour residence times of up to $2500 \mathrm{~s}$, allowing the simulation of fast and slow pyrolysis processes for any lignocellulosic feedstock with known composition [38]. The bio-oil produced is modelled at a high level of detail, with 33 components including organic acids, aldehydes, alcohols, ketones, phenols, sugar 
109

110

composition. The input required by the model for calculating the pyrolysis products is listed in Table 1, while the reactor model is described more in detail in the following.

Table 1. Biomass composition parameters as required by the reaction model.

\begin{tabular}{|c|c|c|}
\hline \multicolumn{3}{|c|}{ BIOMASS COMPOSITION } \\
\hline $\begin{array}{l}\text { ULTIMATE } \\
\text { ANALYSIS } \\
\% \text { wt (db) }\end{array}$ & $\begin{array}{c}\text { PROXIMATE } \\
\text { ANALYSIS } \\
\% \text { wt (ar) }\end{array}$ & $\begin{array}{c}\text { Biochemical } \\
\text { composition } \\
\% \text { wt (db) }\end{array}$ \\
\hline $\begin{array}{c}\text { ASH } \\
\text { CARBON } \\
\text { HYDROGEN } \\
\text { NITROGEN } \\
\text { CHLORINE } \\
\text { SULFUR } \\
\text { OXYGEN } \\
\text { Alkali metal } \\
\text { content }\end{array}$ & $\begin{array}{c}\text { Fixed carbon } \\
\text { Volatile matter } \\
\text { Ash } \\
\text { Water }\end{array}$ & $\begin{array}{c}\text { Cellulose } \\
\text { Hemicellulose } \\
\text { Lignin }\end{array}$ \\
\hline
\end{tabular}

\subsection{Decomposition reactions}

In the first stage, the biomass feedstock is decomposed into its principal building blocks (cellulose, lignin and hemicellulose). This reaction step does not represent any part of the actual pyrolysis reaction mechanism, but is necessary for the following interlinked reaction model. This is based on the three principal building blocks of the biomass and therefore requires these fractions as inputs. Hemicellulose and cellulose are represented in the simulation by its monomers, $\mathrm{C}_{5} \mathrm{H}_{8} \mathrm{O}_{4}$ (Xylan) and $\mathrm{C}_{6} \mathrm{H}_{10} \mathrm{O}_{5}$ (Xylose- like cellulose monomer), respectively. While cellulose and hemicellulose are compounds with relatively fixed monomer structure, lignin is more heterogeneous and can give a wide range of different monomers when decomposing. Lignin is therefore represented by seven different monomers with different $\mathrm{O} / \mathrm{C}$ and $\mathrm{H} / \mathrm{C}$ - ratios. The detailed description of these monomers and their molecular structure can be found in the online supplementary information (SI). Using different lignin monomers permits adjusting the elemental composition of the decomposition products to the elemental composition of the biomass by varying the amounts of the different lignin components [39]. The amount of each of the seven lignin monomers released hence depends on the initial biomass composition. The decomposition reaction is implemented in Aspen Plus in an RYield-type reactor. The yields are calculated iteratively by an embedded Excel worksheet which determines the lignin composition of the biomass according to its elemental composition. More details about the calculation algorithm are provided, together with the properties and molecular structures of the compounds, in the SI. The nitrogen content of the biomass is taken into account by including two representative $\mathrm{N}$ containing species in the decomposition products, glutamic acid and pyrrole, again with different $\mathrm{O} / \mathrm{C}$ and $\mathrm{H} / \mathrm{C}$ ratios to adapt to different biomass compositions. Both are frequent in biomass, the amino acid represents proteins while pyrrole is the basic compound of more complex, biomass typical molecules like chlorophyll or porphyrins [40-42].

\subsection{Primary pyrolysis reactions}


In the second phase, a kinetic reaction model is implemented for the primary pyrolysis reactions. It is an interlinked model of individual decomposition reactions of cellulose, hemicellulose and lignins, according to Miller \& Bellan [43] and Di Blasi [36]. A good review of kinetic model schemes for pyrolysis reactions is given by C. Gómez Díaz in her thesis [44]. The reaction mechanism is based on several works published on the kinetics of pyrolysis reactions [39,4549]. It implements 149 individual reactions, including primary decomposition, secondary decomposition, radical substitution, recombination and char volatilization reactions. The reactor type can be chosen according to the pyrolysis reactor that wants to be modelled. For fast pyrolysis, the RCStir reactor is used, while the RBatch- type reactor is more suitable for slow pyrolysis modelling. For modelling different reactor types, the operation temperature, bed and vapour residence times for the simulated reactor are required as key parameters determining the reactor conditions.

The kinetic reaction schemes are implemented as Power Law type kinetic expressions with the reaction rate calculated in AspenPlus by Equation (1).

$$
r=k * T^{n} * e^{-E / R T}
$$

Equation (1)

With $r$ being the rate of reaction, $k$ the pre-exponential factor, $T$ the absolute temperature, $E$ the activation energy and $R$ the gas law constant.

The complete set of kinetic reactions implemented in the reactor model is given in the supplementary information (SI). All compounds used are listed with their formulae and, if required, their elemental structure which can also be found in the SI.

\subsection{Secondary pyrolysis reactions}

Secondary vapour phase reactions are complex, including partially catalytic polymerization and recombination reactions for which the kinetics are largely unknown $[44,50]$. Nevertheless, they are important and responsible for decreasing oil yields at longer hot vapour residence times. The kinetic reaction mechanism does not include them and therefore tends to give too high oil and too low char yields under slow pyrolysis conditions. To account for them without knowing the underlying kinetic reaction mechanisms, a linear regression model based on experimental results is implemented for this purpose [44,51-53]. Increased gas and char yield due to heterogeneous secondary reactions depend mainly on ash alkali metal content, temperature and vapour residence time [51-53]. The alkali metals contained in the ashes are of special importance since they act like a catalyst for these reactions [54,55]. Based on the experimental findings from literature, a polynomial approximation is implemented that corrects the fractional yields accordingly. In this way, the secondary vapour reactions at longer residence times are accounted for and realistic yields for slow pyrolysis reactors can be obtained.

All the secondary reactions are implemented in Aspen Plus as an embedded Excel sheet which determines the yields of the RYield type secondary reactions reactor. The complete methodology and the corresponding equations can be found in the SI.

\section{Verification with literature data}


In order to validate the reaction model as a predictive tool, it is first tested and cross-checked against data published in literature. In a previous publication, yield curves for different residence times and reaction temperatures for pine wood and wheat straw have been presented [34]. These show the typical shape for biomass pyrolysis, and also the dependency of the yields on the feedstock is represented properly; with pine wood showing a significantly higher liquid yield than wheat straw and a less pronounced response to hot vapour residence time. Apart from generic and typical yield curves, only a few publications are available for in depth verification of the reaction model. The reaction model requires a set of biomass property parameters (above all elemental and biochemical composition), which are usually not given completely in publications on pyrolysis experiments. If, on the other hand, part of the required information (e.g. the biochemical biomass composition) is taken from other works or a common database like Phyllis [56], the significance of the validation is considerably reduced, since the composition of biomass of even the same type can vary substantially. Nevertheless, a few publications are available that include details of the underlying experiments for the simulation. The results are given in Table 2 (fast pyrolysis), and Table 3 (slow pyrolysis). The experimental findings from the available literature are reproduced with good agreement; only the water content of the bio-oil shows some deviation. Also the slow pyrolysis yields correspond well. Straw as a feedstock is included in Table 2 for comparison purpose, although no publication is available that provides all parameters. The influence of the biomass composition on the yields can be clearly observed, with straw as a feedstock showing lower oil and higher char yields.

Table 2. Fraction yields (fast pyrolysis, $500^{\circ} \mathrm{C}$ ) in comparison with literature data.

\begin{tabular}{|c|c|c|c|c|c|c|c|c|}
\hline & \multicolumn{2}{|c|}{ Pine wood } & \multicolumn{2}{|c|}{ Eucalyptus } & \multicolumn{2}{|c|}{ Hybrid Poplar } & \multicolumn{2}{|c|}{ Wheat straw } \\
\hline & Sim & Lit ${ }^{(a)}$ & Sim & Lit ${ }^{(a)}$ & Sim & Lit $^{(b)}$ & Sim & Lit (c) \\
\hline Gas & $10.6 \%$ & $10.9 \%$ & $12.8 \%$ & -- & $12.1 \%$ & $13.1 \%$ & $13.8 \%$ & -- \\
\hline Oil & $75.4 \%$ & $78.3 \%$ & $69.9 \%$ & $70.8 \%$ & $70.9 \%$ & $69.7 \%$ & $66.8 \%$ & -- \\
\hline Char & $14.0 \%$ & $10.9 \%$ & $17.3 \%$ & -- & $17.0 \%$ & $16.2 \%$ & $19.4 \%$ & -- \\
\hline Oil water content & $18.4 \%$ & $23.8 \%$ & $20.7 \%$ & $16.0 \%$ & $16.2 \%$ & $15.8 \%$ & $18.3 \%$ & -- \\
\hline
\end{tabular}

(a): Oasmaa et al. [57]; (b): Ringer et al. [12]; (c): no data available

Table 3. Fraction yields (slow pyrolysis, $425^{\circ} \mathrm{C}$ ) in comparison with literature data.

\begin{tabular}{lcc} 
& \multicolumn{2}{c}{ Pine wood } \\
& Sim & Lit $^{(*)}$ \\
\hline Gas & $27.0 \%$ & $27.2 \%$ \\
Oil & $50.1 \%$ & $49.6 \%$ \\
Char & $22.9 \%$ & $23.0 \%$ \\
\hline
\end{tabular}

Another important aspect of the reaction model is the detailed modeling of the bio-oil composition. Since the analysis of the composition of bio-oil in general is difficult, very little literature is available that provides an analysis of the fractional composition of the bio-oil in combination with all biomass property parameters required for the reaction model. Table 4 shows the comparison of the fractional composition of the bio-oil from two different feedstocks from literature and obtained from simulation. Again, a good agreement can be observed, with the simulation showing a tendency to give higher aldehyde contents and lower water yields. On 
the other hand, the analysis from the literature source does not list ketones and organic acids, which are important constituents of bio-oils.

Table 4. Fractional composition of the bio-oil in comparison with literature data [57].

\section{Pine Wood}

\begin{tabular}{|c|c|c|c|c|}
\hline & & \\
\hline & Sim & Lit & Sim & Lit \\
\hline Water & $18.39 \%$ & $23.8 \%$ & $20.67 \%$ & $25 \%$ \\
\hline Acids & $4.17 \%$ & -- & $6.69 \%$ & -- \\
\hline Aldehydes & $22.34 \%$ & $21.4 \%$ & $18.94 \%$ & $25 \%$ \\
\hline Ketones & $5.03 \%$ & $--(*)$ & $3.68 \%$ & $-\left(^{*}\right)$ \\
\hline Degraded sugars & $29.20 \%$ & $33.3 \%$ & $31.01 \%$ & $30 \%$ \\
\hline Others (extract.) & $3.12 \%$ & $3.6 \%$ & $5.05 \%$ & $2 \%$ \\
\hline Degraded lignin & $17.76 \%$ & $17.9 \%$ & $13.96 \%$ & $17 \%$ \\
\hline
\end{tabular}

212

213

214

215

216

217

218

219

220

221

222

223

224

225

226

227

228

230

231

232

233

234

235

236

237

238

239

$\left({ }^{*}\right)$ : Ketones not listed explicitly, but included in aldehyde fraction

\section{Eucalyptus}

\section{Experimental verification}

As mentioned, literature for verification is scarce, since a set of input variables is required that is often not given completely. If, on the other hand, one or more of the parameters (e.g. the biochemical composition) is taken from another source, the value of the validation is limited. Hence, our own pyrolysis experiments are used for further verifying the model.

\subsection{Experimental setup}

Pyrolysis experiments were conducted in a $1 \mathrm{~kg} \cdot \mathrm{h}^{-1}$ fast pyrolysis unit, using beech wood as feedstock. In order to validate the temperature response of the simulation model, several runs were conducted at different temperatures $\left(450^{\circ} \mathrm{C}, 500^{\circ} \mathrm{C}, 550{ }^{\circ} \mathrm{C}\right)$.

The biomass samples were dried and ground to the particle size required for the pyrolysis reactor. The moisture and ash contents of the biomass samples were determined and their elemental composition analysed. For determining the biochemical compositions, an acid hydrolysis procedure was used. The results of the biomass analysis are given in Tables 5 and 6 .

Table 5. Elemental composition of the beech wood feedstock (\%).

\begin{tabular}{cccccccc} 
C & H & N & Cl & S & O & Ash & Alk* \\
\hline 48.45 & 6.12 & 0.15 & 0 & 0.02 & 45.08 & 0.19 & 0.12 \\
\hline
\end{tabular}

* Alk = Alkali metal content; double counted, already contained in ash

Table 6. Biochemical composition of the beech wood feedstock (\%).

\begin{tabular}{cccccc} 
Water & Cellulose & Hemicellulose & Lignin & Ash & Others \\
\hline 12.95 & 40.26 & 21.68 & 19.91 & 1.62 & 3.58 \\
\hline
\end{tabular}

The fast pyrolysis reactor is a fluidized bed reactor. The reactor bed consists of $1 \mathrm{~kg}$ quartz sand heated electrically and fluidized with pre-heated nitrogen. Two cyclones, a quench column and an electrostatic precipitator (ESP) separate and recover the pyrolysis products. As a quench liquid, a mixture of hydrocarbon isomers (ISOPAR) is used. Since the quench liquid is maintained at a temperature of $30{ }^{\circ} \mathrm{C}$ a significant amount of the process water is in the vapour phase, so an additional condensing system consisting of a water cooled condenser and two dry 
ice/acetone condensers cool the vapours to around $0{ }^{\circ} \mathrm{C}$. This condenses almost all the water and light organics still contained in the gas stream and thereby yields a small amount of secondary condensates, improving the mass balance closure significantly. The running time for the verification experiments was $1.5 \mathrm{~h}$ for each run, processing about $1.5 \mathrm{~kg}$ of biomass feedstock. The hot vapour residence time in the reactor was around 1.5 seconds. The char recovered by the cyclones was collected, weighted and its elemental composition analysed. The gas stream obtained after condensing the water was measured (based on the measured volumetric flow) and analysed every three minutes by on-line gas chromatography (GC; Varian micro gas chromatograph (P-4900). The condensed liquid, the bio-oil, was recovered and separated from the quench liquid by decanting and centrifugation. The water content of the biooil and the secondary condensate was then determined by Karl-Fischer titration. For analysing the composition of the bio-oil, gas chromatography and mass spectroscopy (GC/MS; Varian 450 GC with FID and Varian 220 MS detector) was used. For this purpose, the bio-oil was dissolved in ethanol and injected into the GC. In the same way, the secondary condensates obtained from the dry ice/acetone condensers were analysed, as they contain a significant amount of light organic substances.

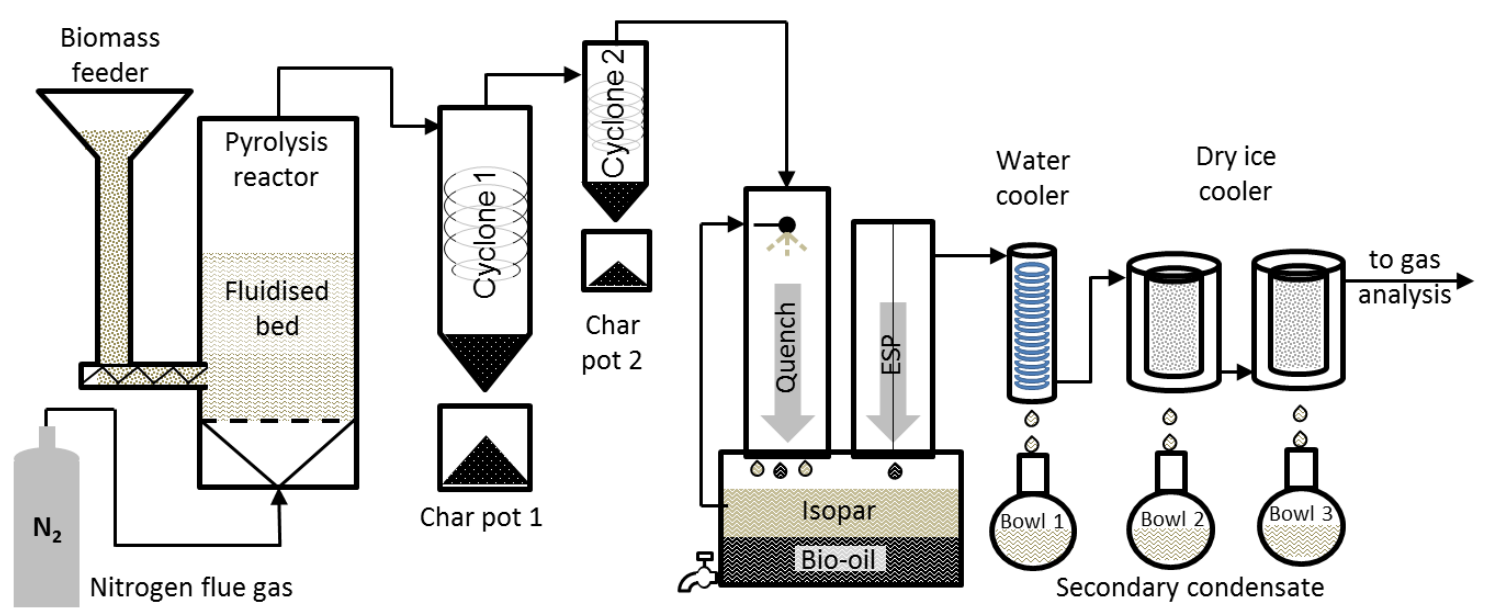

Figure 2. Setup of the experimental fast pyrolysis installation

\subsection{Simulation setup}

260

In order to simulate the pyrolysis experiments, the same process parameters as in the experiments were used for the simulation. The gas residence time in the pyrolysis reactor was 1.5 seconds for all runs. Figure 3 shows a flowsheet of the simulation as used for reproducing the experimental runs. The pyrolysis reactor itself is represented by the three sub-reactors required for modelling the pyrolysis reactions as described previously. The simulation further uses one cyclone instead of the two in the experiments, and the gas-liquid separation is modelled by a flash at ambient pressure and ambient temperature. For this purpose, the condenser cools the quenched product stream down to $25^{\circ} \mathrm{C}$. Although the dry ice/acetone condensers in the experimental setup cool down the gas stream to temperatures around $0{ }^{\circ} \mathrm{C}$, this is considered more realistic, since the condensate is obtained at ambient temperature. 


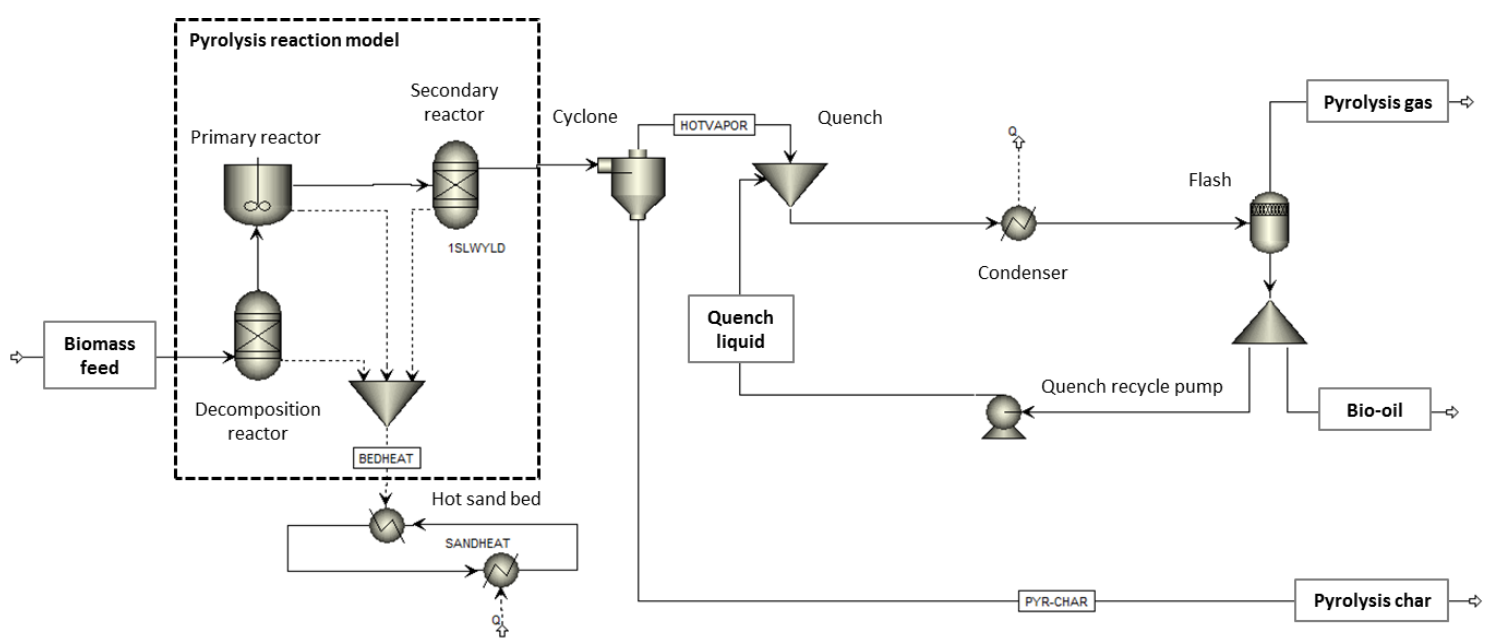

Figure 3. Flowsheet of the AspenPlus simulation setup as used for verification

Furthermore, the lignin composition of the feedstock has to be determined as input for the reaction model. This is done by the iterative calculation procedure implemented in MS-Excel which adjusts the lignin composition to the given elemental and biochemical composition of the biomass. The lignin composition obtained in this way for the beech wood feedstock is presented in Table 7; details about the properties and elemental structure of the lignin fractions can be found in the SI.

Table 7. Lignin composition of the beech wood as used for the simulation

\begin{tabular}{lr} 
Lignin monomer & share \\
\hline Lignin C & $0.24 \%$ \\
Lignin O & $31.88 \%$ \\
Lignin H & $21.49 \%$ \\
LIG-M2 & $18.41 \%$ \\
LIG & $0.35 \%$ \\
PLIG-C & $0.44 \%$ \\
LIG-H & $27.18 \%$ \\
\hline
\end{tabular}

\subsection{Verification results}

The results obtained from the experimental runs are compared with the simulation results in Tables 5 to 7. The analysis of bio-oil via gas chromatography (GC/MS) is generally difficult, and even with advanced methods and at the expense of considerable time only a few of the bio-oil compounds can actually be identified reliably [59]. Within the limited time available, only a CHN analysis of the bio-oil could be done, but with no detailed analysis of the bio-oil. Hence, only the elemental composition of the bio-oil is available for verification. The different runs are named with a number, denominating the reaction temperature in ${ }^{\circ} \mathrm{C}$. The actual reactor bed temperature as measured by the thermocouples during the experiments is slightly higher than the target temperature, giving actual pyrolysis temperatures of 470,520 and $570{ }^{\circ} \mathrm{C}$.

The influence of reactor temperature on the pyrolysis products can be observed in Table 8, with the liquid yield achieving a maximum around $520^{\circ} \mathrm{C}$. The yields of solids increase with lower 
pyrolysis temperature due to incomplete pyrolysis, while it remains almost constant when increasing temperatures to $570^{\circ} \mathrm{C}$. Mass closures of between $95.1 \%$ and $99.9 \%$ are achieved in the experimental runs. The simulation results agree very well with the experimental findings, with the highest correlation around $500^{\circ} \mathrm{C}$ and slightly increasing deviation for temperatures above and below. The temperature behaviour of the simulation in general is slightly less pronounced than in the experiments.

Table 8. Fraction yields (\%) obtained in the experiments and from the simulation. The number denominates the reactor temperature of the run.

\begin{tabular}{lllllll} 
& $\mathbf{4 7 0}$ & & $\mathbf{5 2 0}$ & & $\mathbf{5 7 0}$ \\
& Exp. & Sim. & Exp. & Sim. & Exp. & Sim. \\
\hline Gas & 19.07 & 14.88 & 19.34 & 18.81 & 24.27 & 21.97 \\
Oil & 66.56 & 66.28 & 67.13 & 69.78 & 60.54 & 65.98 \\
Char & 14.27 & 18.82 & 10.62 & 11.39 & 10.31 & 12.03 \\
Mass closure & 99.89 & 99.99 & 97.10 & 99.99 & 95.12 & 99.99 \\
\hline Oil water cont & 26.48 & 28.64 & 29.32 & 28.65 & 33.13 & 30.58
\end{tabular}

The elemental composition obtained for the bio-oils from the experiments and the simulation runs are given in Table 6 . When comparing the bio-oil composition with the elemental composition of the biomass, it can be seen that no fundamental changes occur; the hydrogen content increases and the carbon content decreases slightly, but no significant deoxygenation takes place. In general, the elemental composition of the bio-oil seems to be little affected by the reactor temperature; it is almost identical for the three beech wood runs. This is the case for both experiments and simulation, with the latter giving only slightly higher carbon and lower hydrogen content for the bio-oil (Table 9).

Table 9. Bio-oil composition (\%, ash free) obtained in the experiments and from the simulation. The number denominates the reactor temperature of the run.

\begin{tabular}{clllllll} 
Compound & $\mathbf{4 7 0}$ & & $\mathbf{5 2 0}$ & & $\mathbf{5 7 0}$ & \\
& Exp. & Sim. & Exp. & Sim. & Exp. & Sim. \\
\hline C & 45.64 & 49.00 & 45.17 & 49.40 & 45.08 & 49.91 \\
H & 8.49 & 6.80 & 7.85 & 6.87 & 7.87 & 6.94 \\
$\mathbf{N}$ & 0.10 & 0.14 & 0.10 & 0.14 & 0.10 & 0.14 \\
$\mathbf{O}$ & 45.78 & 44.06 & 46.88 & 43.59 & 46.95 & 43.00 \\
\hline
\end{tabular}

Table 10 provides the detailed bio-oil composition broken down to basic bio-oil constituents as obtained from the simulation (detailed composition by functional groups). The quick degradation of the anhydrous sugar components, above all levoglucosan, can be observed with increasing temperature, while the degraded lignin fraction is independent of the pyrolysis temperature.

Table 10. Detailed composition of the bio-oils (\%) obtained from the simulation. The number denominates the reactor temperature of the run. 


\begin{tabular}{lrrr} 
Water & 28.64 & 28.65 & 30.58 \\
Acids & 6.80 & 6.11 & 6.24 \\
Aldehydes & 7.68 & 16.07 & 21.82 \\
Ketones & 1.66 & 3.44 & 4.73 \\
PAH & 0.00 & 0.04 & 0.07 \\
Sugar derived & 30.46 & 19.52 & 7.68 \\
Furans & 1.95 & 5.12 & 7.26 \\
Alcohols & 4.28 & 4.08 & 4.38 \\
Lignin derived & 17.86 & 16.32 & 16.57 \\
Nitrogen & 0.66 & 0.65 & 0.66 \\
\hline
\end{tabular}

The elemental composition of the chars obtained is determined in the same way, with the corresponding results given in Table 11. Sulphur and chlorine content could not be determined by the available equipment and are not considered in the experimental runs. The char composition shows a maximum carbon content at $500^{\circ} \mathrm{C}$, decreasing with lower and with higher temperatures. The simulation shows a more pronounced temperature behaviour and tends to give higher carbon yields and lower oxygen contents than the experiments for higher pyrolysis temperatures. However, overall the general temperature behaviour is reproduced fairly, and so also are the different results obtained for the two different feedstocks. For temperatures around $500^{\circ} \mathrm{C}$, results are very similar to the experiments, while again the discrepancies increase for higher and lower temperatures. The $\mathrm{N}$ content of the char is similar, but again the temperature behaviour is less pronounced.

Table 11. Char composition (\%; ash free base) obtained in the experiments and from the simulation. The number denominates the reactor temperature of the run. -- = not measured

\begin{tabular}{|c|c|c|c|c|c|c|}
\hline \multirow[t]{2}{*}{ Compound } & \multicolumn{2}{|l|}{470} & \multicolumn{2}{|l|}{520} & \multicolumn{2}{|l|}{570} \\
\hline & Exp. & Sim. & Exp. & Sim. & Exp. & Sim. \\
\hline C & 79.58 & 72.46 & 85.04 & 93.63 & 80.02 & 91.45 \\
\hline H & 3.60 & 3.06 & 3.81 & 1.26 & 3.05 & 2.25 \\
\hline 0 & 16.57 & 24.11 & 10.79 & 4.63 & 16.82 & 5.92 \\
\hline $\mathbf{N}$ & 0.25 & 0.28 & 0.37 & 0.32 & 0.11 & 0.23 \\
\hline $\mathbf{S}$ & -- & 0.09 & -- & 0.16 & -- & 0.15 \\
\hline $\mathrm{Cl}$ & -- & 0.00 & -- & 0.00 & -- & 0.00 \\
\hline
\end{tabular}

\section{Discussion}

A good agreement can be observed between the experimental and the simulation results regarding fractional yields. The prediction of the yields is good and the temperature response also matches well. Highest agreement is found for typical pyrolysis temperatures of around $500^{\circ} \mathrm{C}$, with slightly increasing error towards higher and lower temperatures (Table 5). A similar result can be observed for the water content of the bio-oil, again with highest agreement for reaction temperatures of around $500^{\circ} \mathrm{C}$. The simulation gives slightly lower water contents in comparison with the experiments, an effect that can also be observed when compared to existing literature data [38]. Furthermore, the increase in water content of the oil with increasing temperature is slightly more pronounced for the experimental findings; this indicates an 
increasing error in the prediction of the water content at temperatures above or below the typical pyrolysis temperature of $520{ }^{\circ} \mathrm{C}$. Still, the agreement between experiments and simulation in general is high.

Regarding the product compositions, a good correlation can be found for the atomic composition of the chars and for the bio-oils, with the best matching results at around $500^{\circ} \mathrm{C}$, The simulation further tends to give a higher content of nitrogen containing species in the biooil. However, a good match is obtained for the $\mathrm{N}$ fraction of the char, except for higher pyrolysis temperatures, where the strong decrease of $\mathrm{N}$ observed in the experiments is not reproduced by the simulation. The content of $\mathrm{S}$ and $\mathrm{Cl}$ of the char was not analysed in the experiments and can therefore not be compared.

A detailed analysis of the fractional composition of the bio-oil from the experiments could not be achieved. The results that were obtained by conventional GC/MS analysis of the bio-oil were found to be unsuitable for verification since the results are fundamentally different to the typical values published widely in the literature [6,60-63]. This is in-line with the findings published by Brodzinski in her dissertation [59], who analysed bio-oil and found the light aldehyde and volatile acid content of the bio-oil to be undetectable via conventional GC/MS, since the solvent peaks cover the peaks of these volatile compounds. Nevertheless, a qualitative validation can be done with the data published by Brodzinski, who gives an exhaustive analysis of a bio-oil obtained from beech wood. Figure 4 gives a comparison of the bio-oil composition obtained in her work for beech wood ( $8.9 \%$ moisture) with the one obtained from the simulation. Comparison is done on a dry base, since the beech wood used by Brodzinski had a lower water content. Good agreement is found for the proportion of degraded lignins, organic acids and ketones, while for the alcohol, aldehyde and especially, the degraded sugar fraction significantly higher proportions are obtained. On the other hand, almost $44 \%$ of the bio-oil remains unidentified by Brodzinski, and hence must be part of one of the fractions.
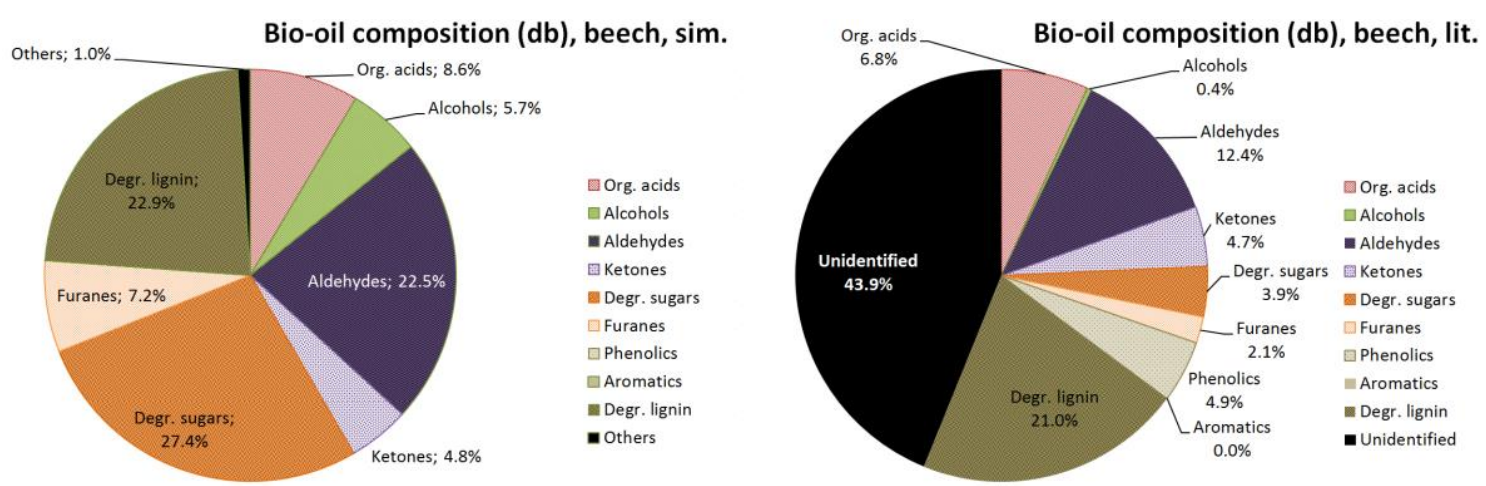

Figure 4. Comparison of the composition of beech wood bio-oil obtained from simulation (left) and from literature [59] (right); dry base

\section{Conclusions}

The kinetic reaction model presented in this paper as implemented in Aspen Plus predicts the pyrolysis reactions for lignocellulosic biomass as a function of the biomass composition and reactor conditions. It shows the typical yield curves for pyrolysis reactions and with good agreement with existing literature data on pyrolysis yields and product composition. Maximum bio-oil yield is predicted for temperatures around $500^{\circ} \mathrm{C}$, and oil yields are notably higher for a 
woody feedstock like pine wood than for straw. Only for higher temperatures above the range of typical pyrolysis conditions, an increasing error can be observed, which limits the applicability of the model for extreme conditions. The experimental validation in a $1 \mathrm{~kg} \cdot \mathrm{h}^{-1}$ continuous fluidised bed reactor in the installations of the Bioenergy Research Group (BERG) of Aston University further underlines these findings. A high agreement regarding fraction yields and water content of the bio-oil can be observed, and also for the elemental composition of the biooil and the char product. While a detailed determination of the fractional composition of the bio-oil obtained from the experiments was not possible, a comparison with published work on the composition of bio-oil from beech wood produced under similar conditions shows good agreement. The reaction model can therefore be considered a valuable tool for calculating the yields and the composition of the products for pyrolysis of lignocellulosic biomass.

Up to now, process analysis of pyrolysis processes used simple models based on black box approaches and with a strongly simplified composition of the bio-oil. This is the first work that presents a comprehensive kinetic reaction model that can be readily implemented in AspenPlus and similar process simulation software packages. The predictive approach and the detailed modelling of the bio-oil allows a better estimation of the properties of bio-oils obtained from different types of lignocellulosic biomass under different pyrolysis conditions (including fast and slow pyrolysis) without the need for case-specific pyrolysis experiments. As such, it will permit quicker and more reliable system analysis of all kind of pyrolysis processes. The detailed information about stream compositions that can be obtained from the model also eases the analysis and optimisation of pyrolysis processes on a plant level, allowing more precise thermodynamic and economic assessments, but also the estimation of potential environmental impacts of such processes.

\section{Acknowledgements}

We would like to thank the BRISK initiative for financing access to the pyrolysis facilities and the EBRI, Aston University for providing their installations and for their support. Further we thank the CIEMAT, Madrid for the biochemical analysis of the biomass feedstocks. This research has been partly supported by the Spanish Ministry of Economy and Competitiveness (IPT-20120219-120000).

\section{Literature:}

[1] Scarlat N, Dallemand J-F, Monforti-Ferrario F, Nita V. The Role of Biomass and Bioenergy in a Future Bioeconomy: Policies and Facts. Environ Dev 2015;15:334. doi:10.1016/j.envdev.2015.03.006.

[2] Bridgwater A V. Biomass Fast Pyrolysis. Therm Sci 2004;8:21-49.

[3] Kan T, Strezov V, Evans TJ. Lignocellulosic biomass pyrolysis: A review of product properties and effects of pyrolysis parameters. Renew Sustain Energy Rev 2016;57:1126-40. doi:10.1016/j.rser.2015.12.185.

[4] Meier D, van de Beld B, Bridgwater A V, Elliott DC, Oasmaa A, Preto F. State-ofthe-art of fast pyrolysis in IEA bioenergy member countries. Renew Sustain 
[5] Bridgwater A V. Review of fast pyrolysis of biomass and product upgrading. Biomass and Bioenergy 2012;38:68-94. doi:10.1016/j.biombioe.2011.01.048.

[6] Oasmaa A, Peacocke C. Properties and fuel use of biomass-derived fast pyrolysis liquids. A guide. VTT Publication 731. Espoo, Finland: VTT Technical Research Centre of Finland: 2010.

[7] Jones SB, Valkenburg C, Walton CW, Elliott DC, Holladay JE, Stevens DJ, et al. Production of Gasoline and Diesel from Biomass via Fast Pyrolysis, Hydrotreating and Hydrocracking : A Design Case. Washington, United States: Pacific Northwest National Laboratory: 2009.

[8] Anex RP, Aden A, Kazi FK, Fortman J, Swanson RM, Wright MM, et al. Technoeconomic comparison of biomass-to-transportation fuels via pyrolysis, gasification, and biochemical pathways. Fuel 2010;89:29-35. doi:10.1016/j.fuel.2010.07.015.

[9] Wright MM, Satrio JA, Brown RC, Daugaard DE, Hsu DD. Techno-Economic Analysis of Biomass Fast Pyrolysis to Transportation Fuels. Golden, United States: National Renewable Energy Laboratory: 2010.

[10] Sadhukhan J, Ng KS. Economic and European Union Environmental Sustainability Criteria Assesment of Bio-Oil-Based Biofuel Systems: Refinery Integration Cases. Ind Eng Chem Res 2011;50:6794-808. doi:10.1021/ie102339r.

[11] Swanson RM, Satrio JA, Brown RC, Platon A, Hsu DD. Techno-Economic Analysis of Biofuels Production Based on Gasification. Golden, United States: National Renewable Energy Laboratory: 2010. doi:10.2172/994017.

[12] Ringer M, Putsche V, Scahill J. Large-Scale Pyrolysis Oil Production: A Technology Assessment and Economic Analysis. Golden, United States: National Renewable Energy Laboratory: 2006. doi:10.2172/894989.

[13] Zaimes GG, Soratana K, Harden CL, Landis AE, Khanna V. Biofuels via Fast Pyrolysis of Perennial Grasses: A Life Cycle Evaluation of Energy Consumption and Greenhouse Gas Emissions. Environ Sci Technol 2015;49:10007-18. doi:10.1021/acs.est.5b00129.

[14] Shemfe MB, Gu S, Ranganathan P. Techno-economic performance analysis of biofuel production and miniature electric power generation from biomass fast pyrolysis and bio-oil upgrading. Fuel 2015;143:361-72.

doi:10.1016/j.fuel.2014.11.078.

[15] Eikeland MS, Thapa RK, Halvorsen BM. Aspen Plus Simulation of Biomass Gasification with Known Reaction Kinetic. 56th Conf. Simul. Model. (SIMS 56), Linköping, Sweden: 2015, p. 149-56. doi:10.3384/ecp15119149.

[16] Al-Malah KIM. Reactors with Complex (Non-Conventional) Reaction Kinetic Forms. Aspen Plus ${ }^{\circledR}$, Hoboken, NJ, USA: John Wiley \& Sons, Inc.; 2016, p. 197227. doi:10.1002/9781119293644.ch7.

[17] Al-Malah KIM. Reactors with Simple Reaction Kinetic Forms. Aspen Plus ${ }^{\circledR}$, 
Hoboken, NJ, USA: John Wiley \& Sons, Inc.; 2016, p. 155-96. doi:10.1002/9781119293644.ch6.

[18] Lestinsky P, Palit A. Wood Pyrolysis Using Aspen Plus Simulation and Industrially Applicable Model. Geosci Eng 2016;62:11-6. doi:10.1515/gse-2016-0003.

[19] Lee YR, Choi HS, Park HC, Lee JE. A numerical study on biomass fast pyrolysis process: A comparison between full lumped modeling and hybrid modeling combined with CFD. Comput Chem Eng 2015;82:202-15. doi:10.1016/j.compchemeng.2015.07.007.

[20] Papadikis K, Gu S, Bridgwater A V, Gerhauser H. Application of CFD to model fast pyrolysis of biomass. Fuel Process Technol 2009;90:504-12. doi:10.1016/j.fuproc.2009.01.010.

[21] Aramideh S, Xiong Q, Kong S-C, Brown RC. Numerical simulation of biomass fast pyrolysis in an auger reactor. Fuel 2015;156:234-42. doi:10.1016/j.fuel.2015.04.038.

[22] Xue A, Pan J, Tian M, Yi X. Pyrolysis model of single biomass pellet in downdraft gasifier. Trans Tianjin Univ 2016;22:174-81. doi:10.1007/s12209-016-2701-3.

[23] Haseli Y, van Oijen JA, de Goey LPH. A Simplified Pyrolysis Model of a Biomass Particle Based on Infinitesimally Thin Reaction Front Approximation. Energy \& Fuels 2012;26:3230-43. doi:10.1021/ef3002235.

[24] Hough BR, Schwartz DT, Pfaendtner J. Detailed Kinetic Modeling of Lignin Pyrolysis for Process Optimization. Ind Eng Chem Res 2016;55:9147-53. doi:10.1021/acs.iecr.6b02092.

[25] Guan J, Qi G, Dong P. A granular-biomass high temperature pyrolysis model based on the Darcy flow. Front Earth Sci 2015;9:114-24. doi:10.1007/s11707014-0371-9.

[26] Klinger JL. Modeling of biomass torrefaction and pyrolysis and its applications. Michigan Technological University, Michigan, US, 2015.

[27] Klinger J, Bar-Ziv E, Shonnard D. Unified kinetic model for torrefaction-pyrolysis. Fuel Process Technol 2015;138:175-83. doi:10.1016/j.fuproc.2015.05.010.

[28] Jung CG, loannidou O, Zabaniotou A. Validation of a predictive model applied to biomass using pyrolysis laboratory experimental results of agricultural residues. CEB Working Paper Nº8/022. Brussels, Belgium: 2008.

[29] Lerkkasemsan N. Fuzzy logic-based predictive model for biomass pyrolysis. Appl Energy 2016. doi:10.1016/j.apenergy.2016.02.105.

[30] Lerkkasemsan N. Predicting Conversion from Pyrolysis of Pongmia. Energy Procedia 2015;75:192-5. doi:10.1016/j.egypro.2015.07.295.

[31] Sharma A, Pareek V, Zhang D. Biomass pyrolysis-A review of modelling, process parameters and catalytic studies. Renew Sustain Energy Rev 2015;50:1081-96. doi:10.1016/j.rser.2015.04.193.

[32] Peters JF. Pyrolysis for biofuels or biochar? A thermodynamic, environmental 
and economic assessment. 2015.

[33] Peters JF, Petrakopoulou F, Dufour J. Exergy analysis of synthetic biofuel production via fast pyrolysis and hydroupgrading. Energy 2014;submitted.

[34] Peters JF, Banks SW, Susmozas A, Dufour J. Experimental verification of a predictive pyrolysis model in Aspen Plus. 22nd Eur. Biomass Conf. Exhib., Hamburg, Germany: 2014.

[35] Peters JF, Iribarren D, Dufour J. Simulation and life cycle assessment of biofuel production via fast pyrolysis and hydroupgrading. Fuel 2015;139:441-456.

[36] Di Blasi C. Modeling chemical and physical processes of wood and biomass pyrolysis. Prog Energy Combust Sci 2008;34:47-90. doi:10.1016/j.pecs.2006.12.001.

[37] Xiu S, Shahbazi A. Bio-oil production and upgrading research: A review. Renew Sustain Energy Rev 2012;16:4406-14. doi:10.1016/j.rser.2012.04.028.

[38] Peters JF, Iribarren D, Dufour J. Predictive pyrolysis process modelling in Aspen Plus. 21st Eur. Biomass Conf. Exhib., Copenhagen, Denmark: 2013.

[39] Faravelli T, Frassoldati A, Migliavacca G, Ranzi E. Detailed kinetic modeling of the thermal degradation of lignins. Biomass and Bioenergy 2010;34:290-301. doi:10.1016/j.biombioe.2009.10.018.

[40] Hansson K-M, Samuelsson J, Tullin C, Åmand L-E. Formation of HNCO, HCN, and $\mathrm{NH} 3$ from the pyrolysis of bark and nitrogen-containing model compounds. Combust Flame 2004;137:265-77. doi:10.1016/j.combustflame.2004.01.005.

[41] Jusélius J, Sundholm D. The aromatic pathways of porphins, chlorins and bacteriochlorins. Phys Chem Chem Phys 2000;2:2145-51. doi:10.1039/b000260g.

[42] Ren Q, Zhao C. NOx and $\mathrm{N} 2 \mathrm{O}$ precursors ( $\mathrm{NH} 3$ and $\mathrm{HCN}$ ) from biomass pyrolysis: interaction between amino acid and mineral matter. Appl Energy 2013;112:1704. doi:10.1016/j.apenergy.2013.05.061.

[43] Miller RS, Bellan J. A Generalized Biomass Pyrolysis Model Based on Superimposed Cellulose, Hemicellulose and Liqnin Kinetics. Combust Sci Technol 1997;126:97-137. doi:10.1080/00102209708935670.

[44] Gómez Díaz CJ. Understanding Biomass Pyrolysis Kinetics: Improved Modeling Based on Comprehensive Thermokinetic Analysis. PhD Thesis; Universitat Politècnica de Catalunya, Dept. of Chemical Engineering. Barcelona, Spain, 2006.

[45] Dupont C, Chen L, Cances J, Commandre J-M, Cuoci A, Pierucci S, et al. Biomass pyrolysis: Kinetic modelling and experimental validation under high temperature and flash heating rate conditions. J Anal Appl Pyrolysis 2009;85:260-7. doi:10.1016/j.jaap.2008.11.034.

[46] Ranzi E, Cuoci A, Faravelli T, Frassoldati A, Migliavacca G, Pierucci S, et al. Chemical Kinetics of Biomass Pyrolysis. Energy \& Fuels 2008;22:4292-300. doi:10.1021/ef800551t. 
[47] Calonaci M, Grana R, Barker Hemings E, Bozzano G, Dente M, Ranzi E. Comprehensive Kinetic Modeling Study of Bio-oil Formation from Fast Pyrolysis of Biomass. Energy \& Fuels 2010;24:5727-34. doi:10.1021/ef1008902.

[48] Van de Velden M, Baeyens J, Brems A, Janssens B, Dewil R. Fundamentals, kinetics and endothermicity of the biomass pyrolysis reaction. Renew Energy 2010;35:232-42. doi:10.1016/j.renene.2009.04.019.

[49] Graham RG, Bergougnou MA, Freel BA. The kinetics of vapour-phase cellulose fast pyrolysis reactions. Biomass and Bioenergy 1994;7:33-47. doi:10.1016/0961-9534(94)00045-U.

[50] Anca-Couce A, Mehrabian R, Scharler R, Obernberger I. Kinetic scheme of biomass pyrolysis considering secondary charring reactions. Energy Convers Manag 2014;87:687-96. doi:10.1016/j.enconman.2014.07.061.

[51] Hoekstra E, Westerhof RJM, Brilman W, Van Swaaij WPM, Kersten SRA, Hogendoorn KJA, et al. Heterogeneous and homogeneous reactions of pyrolysis vapors from pine wood. AIChE J 2012;58:2830-42. doi:10.1002/aic.12799.

[52] Wang S, Liu Q, Liao Y, Luo Z, Cen K. A study on the mechanism research on cellulose pyrolysis under catalysis of metallic salts. Korean J Chem Eng 2007;24:336-40. doi:10.1007/s11814-007-5060-x.

[53] Aho A, DeMartini N, Pranovich A, Krogell J, Kumar N, Eränen K, et al. Pyrolysis of pine and gasification of pine chars--influence of organically bound metals. Bioresour Technol 2013;128:22-9. doi:10.1016/j.biortech.2012.10.093.

[54] Trendewicz A, Evans R, Dutta A, Sykes R, Carpenter D, Braun R. Evaluating the effect of potassium on cellulose pyrolysis reaction kinetics. Biomass and Bioenergy 2015;74:15-25. doi:10.1016/j.biombioe.2015.01.001.

[55] Wang K, Zhang J, Shanks BH, Brown RC. The deleterious effect of inorganic salts on hydrocarbon yields from catalytic pyrolysis of lignocellulosic biomass and its mitigation. Appl Energy 2015;148:115-20. doi:10.1016/j.apenergy.2015.03.034.

[56] ECN-Biomass. Phyllis Database n.d. http://www.ecn.nl/phyllis2/ (accessed October 12, 2014).

[57] Oasmaa A, Solantausta Y, Arpiainen V, Kuoppala E, Sipilä K. Fast Pyrolysis BioOils from Wood and Agricultural Residues. Energy \& Fuels 2010;24:1380-8. doi:10.1021/ef901107f.

[58] Williams PT, Besler S. The influence of temperature and heating rate on the slow pyrolysis of biomass. Renew Energy 1996;7:233-50. doi:10.1016/09601481(96)00006-7.

[59] Brodzinski I. Methodenentwicklung zur Charakterisierung von Pyrolyseölen aus Biomasse. PhD Thesis; Universität Hamburg, Department Biologie der Fakultät Mathematik, Informatik und Naturwissenschaften. Hamburg, Germany, 2006.

[60] Diebold JP. A Review of the Chemical and Physical Mechanisms of the Storage Stability of Fast Pyrolysis Bio-Oils. Golden, United States: National Renewable Energy Laboratory: 2000. 
602

603

604

605

606

607

608

609

610

611

612

613

614

615

616

617

618

619

620

621

$622 \mathrm{db}$

623

[61] Oasmaa A, Meier D. Pyrolysis Liquids Analyses - The results of IEA-EU Round Robin. In: Bridgwater A V., editor. Fast Pyrolysis Biomass A Handbook. Vol. 2, Birmingham, United Kingdom: CPL Press; 2002, p. 41-58.

[62] Oasmaa A, Peacocke C. A guide to physical property characterisation of biomass-derived fast pyrolysis liquids. Espoo, Finland: VTT Technical Research Centre of Finland: 2001.

[63] Peacocke C. Transport, Handling and Storage of Fast Pyrolysis Liquids. In: Bridgwater A V., editor. Fast Pyrolysis Biomass A Handbook. Vol. 2, Birmingham, United Kingdom: CPL Press; 2002, p. 239-337.

\section{Abbreviations}

ESP Electrostatic precipitator

GC Gas chromatography

MS Mass spectroscopy

RYield Aspen Plus reactor type: Black box type reactor where the yields of the

RGibbs Aspen Plus reactor type: Calculates the reaction products by Gibbs free

RCSTIR Aspen Plus reactor type: Kinetic reactor for simulating reactors with perfect mixing of the reactants; requires specification of the reaction kinetics

RBatch Aspen Plus reactor type: Kinetic reactor for simulating batch type reactors; allows for defining temperature profiles. Requires specification of the reaction kinetics

ULTANAL Ultimate analysis - atomic composition ( $\mathrm{C}, \mathrm{H}, \mathrm{N}, \mathrm{O}, \mathrm{S}, \mathrm{Cl}$ )

PROXANAL Proximate analysis - fractional composition (volatile matter, fixed carbon, water content)

\section{PAH Polycyclic aromatic hydrocarbon}

ar As received

Dry base 